\title{
Indicadores de design para a valorização dos resíduos da construção civil, da Indústria sucroalcooleira e da rizicultura no Maranhão
}

André de Souza Lucca aslucca@yahoo.com.br Universidade Federal do Maranhão (UFMA), São Luís, Maranhão, Brasil

Pâmela Nascimento Oliveira pamela94_oliveira@hotmail.com Universidade Federal do Maranhão (UFMA), São Luís, Maranhão, Brasil

Lucas Franco Corrêa Schalcher lucas_schalcher@hotmail.com Universidade Federal do Maranhão (UFMA), São Luís, Maranhão, Brasil

Letícia Fernanda Brito Moraes leticiafbmoraes@gmail.com Universidade Federal do Maranhão (UFMA), São Luís, Maranhão, Brasil

\begin{abstract}
RESUMO
Baseado nos trabalhos de Levantamento Bibliográfico Narrativo e de Revisão Bibliográfica Sistemática, o presente texto apresenta os resultados relativos a valorização dos resíduos da construção civil, da indústria sucroalcooleira e da rizicultura no Maranhão contidos no relatório técnico de pesquisa sobre as estratégias de design para a valorização dos recursos e produtos locais no território maranhense. A pesquisa teve como objetivo desenvolver um estudo para promover a competitividade das microrregiões maranhenses através da valorização do patrimônio natural local sob a ótica do design sustentável. Este trabalho reflete a premissa de que o uso sustentável da grande diversidade de recursos naturais presentes no estado do Maranhão pode gerar riqueza e melhorar a qualidade de vida de grande parte da população local envolvida com os processos de reaproveitamento, reciclagem e reutilização de resíduos. Como resultado, este trabalho estabeleceu indicadores de design para a valorização dos resíduos da construção civil, da indústria sucroalcooleira e da rizicultura no Maranhão.
\end{abstract}

PALAVRAS-CHAVE: Design sustentável. Design estratégico. Valorização de resíduos. 


\section{INTRODUÇÃO}

Segundo Krucken (2009), países como o Brasil que possuem uma grande diversidade cultural, étnica e de recursos naturais muitas vezes utilizam de forma insustentável seu patrimônio socioambiental deixando de gerar riqueza e melhorar a qualidade de vida de grande parte da população. Criar as condições para que o potencial dos recursos locais se converta em benefício real e durável para as comunidades representa um grande desafio nas economias emergentes.

Para a autora, valorizar os recursos e os produtos locais é um campo de atuação rico e complexo, pois estes produtos envolvem simultaneamente dimensões físicas e cognitivas. É necessário perceber as qualidades do contexto local para compreender as relações que se formam em torno da produção e do consumo dos produtos. A perspectiva do Design vem justamente ajudar nessa complexa tarefa de mediar produção e consumo, tradição e inovação, qualidades locais e relações globais (KRUCKEN, 2009).

Essencialmente ser competitivo significa ser capaz de sustentar a concorrência do mercado, portanto, a competitividade tem a priori um sentido puramente econômico. Entretanto, segundo o Observatório Europeu Leader (2001), um território se torna competitivo quando é capaz de afrontar a concorrência de mercado garantindo, ao mesmo tempo, uma sustentabilidade ambiental, econômica e social baseada na organização em rede e na articulação interterritorial.

Vários autores sustentam que o papel do designer nesse contexto é aquele de servir de enlace entre as exigências dos usuários e dos produtores, de promover sinergias entre as atividades produtivas no território, de facilitar os processos colaborativos e de mediar as diversas disciplinas e conhecimentos envolvidos nos processos projetuais (KOENIG, 1995; DE GIORGI; GERMAK, 2008; THACKARA, 2008; MANZINI, 2008; BISTAGNINO, 2009).

Neste texto são apresentados os resultados relativos à valorização dos resíduos da construção civil, da indústria sucroalcooleira e da rizicultura no estado do Maranhão obtidos com a pesquisa intitulada "Estratégias e indicadores para projetos de valorização de recursos e produtos no território maranhense", desenvolvida durante o período de agosto de 2014 a agosto de 2016 e que contou com auxílio da Fundação de Amparo à Pesquisa e ao Desenvolvimento Científico e Tecnológico do Maranhão - FAPEMA, através do edital no 001/2014 Universal.

\section{MATERIAIS E MÉTODOS}

A pesquisa que gerou este trabalho foi caracterizada por uma abordagem mista (quali-quantitativa), com objetivos exploratórios onde foram empregadas ferramentas estruturadas e não-estruturadas para coleta de dados, como o Levantamento Bibliográfico Narrativo e a Revisão Bibliográfica Sistemática. Tal abordagem permitiu aprofundar o entendimento sobre os conceitos e princípios do Design Sustentável aplicáveis na valorização de recursos locais e, em particular, sobre as estratégias para a implementação de ações de projeto no contexto maranhense. 
Estas ferramentas foram utilizadas sequencialmente durante as três principais etapas de desenvolvimento do trabalho, conforme a Figura 1, permitindo a compreensão dos princípios de design relacionados com a sustentabilidade e a valorização dos recursos locais, a identificação e a escolha dos recursos locais a serem analisados, a identificação das estratégias de design sustentável relacionadas com o contexto maranhense e a definição dos indicadores de projeto específicos para a valorização dos resíduos da construção civil, da indústria sucroalcooleira e da rizicultura no Maranhão.

Figura 1 - Etapas do desenvolvimento da pesquisa

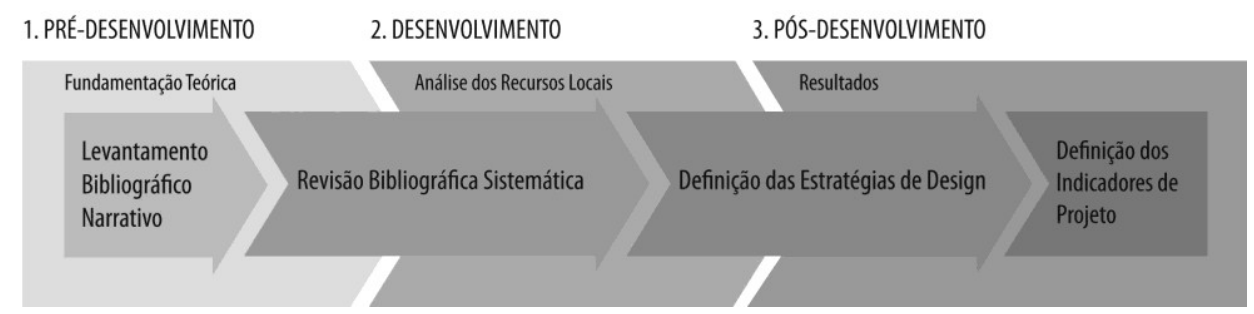

Fonte: Autoria própria (2016)

Na etapa de Pré-desenvolvimento foi efetuada a fundamentação teórica da pesquisa através do Levantamento Bibliográfico Narrativo. Com esta ferramenta se procurou entender o "estado da arte" sobre os princípios de design relacionados com a sustentabilidade e a valorização dos recursos locais a partir de pesquisas recentes em nível de mestrado e doutorado realizadas nos Programas de Pós-graduação em Design ou com linhas de pesquisa em Design no Brasil. Também como fonte para este levantamento foram revisados livros e artigos científicos de áreas complementares ao tema como a Economia Ecológica, o Desenvolvimento Local e a Agricultura Ecológica.

O Levantamento Bibliográfico Narrativo é um estudo que tem por característica permitir estabelecer relações com produções bibliográficas anteriores, identificando temáticas recorrentes e apontando novas perspectivas (ROCHA, 1999 apud VOSGERAU; ROMANOWSKI, 2014).

A etapa de Desenvolvimento da pesquisa foi baseada na Revisão Bibliográfica Sistemática (RBS). Neste momento buscou-se compreender e identificar as características, os usos e as tecnologias envolvidas nos processos de obtenção, manipulação e beneficiamento dos resíduos da construção civil, da indústria sucroalcooleira e da rizicultura através da análise de artigos científicos que descrevem pesquisas no Brasil que abordam estes assuntos.

De acordo com Kitchenham (2004 apud CONFORTO; AMARAL; SILVA, 2011) a RBS busca identificar, avaliar e interpretar as pesquisas disponíveis e relevantes para uma determinada questão de pesquisa ou fenômeno de interesse em determinados bancos de dados.

Ghor et al. (2013) definem o método para produção de RBS em três etapas. A primeira consiste nas "Perguntas de Pesquisa", onde será dado o impulso inicial da revisão. Nesta etapa são definidos o tema no qual se deseja desenvolver a pesquisa e o período em que se buscará o material disponível que se encaixe no assunto proposto. Em seguida são definidas as palavras-chave, que serão usadas 
como identificadores e que indicarão os principais assuntos correspondentes ao tema. Após, seleciona-se a base de dados para a busca.

A segunda etapa trata da "Pesquisa e Seleção", onde após a definição dos critérios que nortearão a pesquisa, inicia-se o levantamento e a seleção dos artigos. As palavras-chave são verificadas no conteúdo do artigo analisado. Ocorre o primeiro filtro dos artigos, fazendo uma seleção a partir da leitura dos títulos, para que se possa identificar os que não são afim com o tema de interesse, já os excluindo do universo de artigos inicial. Nesta etapa, também é realizada a leitura dos resumos, para que se identifique os que não estão alinhados ao tema, excluindo-os. A fase seguinte consiste em uma análise subjetiva dos artigos feita pelo pesquisador, para que se possa identificar nos artigos aqueles que possuem maior relevância com o tema.

A terceira etapa, denominada "Descrição e Classificação", consiste na classificação dos artigos selecionados, onde ocorre a organização dos textos segundo um padrão que varia de acordo com a necessidade do pesquisador.

Neste trabalho, a base de dados selecionada foi o Sistema WebQualis do Portal de periódicos da CAPES, com evento de qualificação Qualis 2014, área de avaliação Engenharias I e classificação dos artigos de A1 até B5.

\section{Os resíduos da construção civil em São Luís do Maranhão}

A cidade de São Luís, capital do estado do Maranhão, passa por um crescente desenvolvimento no setor da construção civil. Nas últimas décadas a cidade verticalizou-se aceleradamente bem como o acúmulo dos resíduos desta atividade. Segundo a Associação Brasileira de Empresas de Limpeza Pública e Resíduos Especiais - ABRELPE (2014), o Brasil em 2013 produziu aproximadamente 117 mil toneladas/dia de resíduos provenientes da construção civil, aumentando $4,6 \%$ em sua produção se comparado com a pesquisa anterior. A região Nordeste é a segunda região que mais gera resíduos no país, ficando atrás apenas da região Sudeste.

Os resíduos das atividades da construção civil se originam principalmente em duas etapas: no processo de construção e quando ocorre a demolição de uma edificação. Por isso, podem ser chamados de Resíduos da Construção Civil (RCC) ou de Resíduos da Construção e Demolição (RCD). Atualmente em São Luís grande parte dos RCD são depositados em lixões ou terrenos não habitados o que, na maioria das vezes, representa um descarte impróprio para tais resíduos.

A lei que orienta a forma correta de armazenar os RCD, assim como os demais resíduos sólidos, é a Lei no 12.305/2010, também chamada de Política Nacional de Resíduos Sólidos (PNRS). Nela está contido um conjunto de medidas que tem a finalidade de instituir hábitos que incentivam a redução da produção, a reciclagem, o reaproveitamento, o manejo e a destinação correta dos resíduos de acordo com as leis ambientais.

Porém, o principal problema que esses resíduos geram é o grande espaço que eles ocupam. Uma alternativa para solucionar este tipo de problema é a sua reciclagem. Segundo a Associação Brasileira para Reciclagem de Resíduos da Construção Civil e Demolição - ABRECON, o Brasil reciclou cerca de 40 mil toneladas de RCD por mês em 2012. Este valor é muito inferior ao ideal, 
considerando que aproximadamente $70 \%$ desse material está apto para ser reciclado.

Segundo a resolução no 307 de 2002 do Conselho Nacional de Meio Ambiente - CONAMA, os resíduos da construção civil são classificados em quatro classes, conforme o Quadro 1.

Quadro 1 - Classificação dos resíduos da construção civil segundo o CONAMA

\begin{tabular}{|c|c|}
\hline Tipo & Descrição \\
\hline Classe A & $\begin{array}{l}\text { São os resíduos reutilizáveis ou recicláveis como } \\
\text { agregados, tais como: argamassa, concreto, tijolo e } \\
\text { terra. }\end{array}$ \\
\hline Classe B & $\begin{array}{l}\text { São os resíduos recicláveis com outras destinações, } \\
\text { tais como: plásticos, papelão, metais, vidros, madeiras } \\
\text { e outros. }\end{array}$ \\
\hline Classe C & $\begin{array}{l}\text { São os resíduos para os quais não foram } \\
\text { desenvolvidas tecnologias ou aplicações } \\
\text { economicamente viáveis que permitam a sua } \\
\text { reciclagem ou recuperação, tais como os produtos } \\
\text { oriundos do gesso e sacaria de cimento. }\end{array}$ \\
\hline Classe D & $\begin{array}{l}\text { São resíduos perigosos tais como tintas, solventes, } \\
\text { óleos e outros ou aqueles contaminados ou } \\
\text { prejudiciais à saúde oriundos de demolições, reformas } \\
\text { e reparos de clínicas radiológicas, instalações } \\
\text { industriais e outros, bem como, telhas e demais } \\
\text { objetos e materiais que contenham amianto ou } \\
\text { outros produtos nocivos à saúde. (Nova redação dada } \\
\text { pela Resolução } n^{\circ} 348 / 04 \text { ). }\end{array}$ \\
\hline
\end{tabular}

Fonte: Próprio autor baseado em Resolução CONAMA no 307 (2002).

A composição dos RCD varia conforme o tipo de atividade e estrutura que os originou, podendo conter materiais volumosos e pesados como concreto, asfalto, gesso, metais, britas, vidros, plásticos, solos e rochas de limpeza de terrenos e escavações, madeiras e compensados, forros, tijolos, blocos cerâmicos, componentes como portas, janelas, tubulações, e, até mesmo, materiais perigosos como resinas, colas, tintas, asbestos e metais pesados (BANIAS et al., 2010).

A maior parte desses resíduos estão inseridos na classe $A$, que são considerados resíduos recicláveis. Por sua vez, a mistura desses resíduos de classe A gera o resíduo misto, que é o resíduo mais abundante encontrado atualmente nas construções em São Luís.

Uma forma para a sua reciclagem é a utilização como matéria prima para a produção de outros materiais utilizáveis na própria atividade da construção civil, como o concreto e as argamassas.

Deste modo, os resíduos podem ser empregados de três formas: como agregados (podendo ser graúdo ou miúdo); como aglomerantes, substituindo totalmente ou parcialmente o cimento ou a cal; e como aditivos, dando características diferenciadas aos materiais.

Os resíduos mais utilizados para a produção de concretos e argamassas são a cerâmica, o gesso, o resíduo misto (a mistura de resíduos de concreto e resíduos cerâmicos) e o granito. 


\section{A indústria sucroalcooleira no Maranhão}

A cana-de-açúcar (Saccharum officinarum) é um dos principais produtos agroindustriais do Brasil e a sua produção está ligada com a própria história do país. De acordo com Machado (2015) foi Martim Affonso de Souza que em 1532 trouxe a primeira muda de cana-de-açúcar para o Brasil e iniciou seu cultivo na Capitania de São Vicente. A cultura da cana-de-açúcar e a produção do açúcar nos engenhos se multiplicaram no país no período da colonização, época em que Brasil monopoliza a produção mundial e o açúcar se torna o principal produto de exportação nacional.

Ainda hoje o cultivo da cana-de-açúcar é um importante produto do agronegócio brasileiro e conta com vantagens competitivas, como a grande disponibilidade de terras, as condições climáticas favoráveis em grande parte do país, uma vasta experiência no cultivo e os baixos custos de produção. Segundo os dados do Companhia Nacional de Abastecimento - CONAB (2009), apesar da cana-de-açúcar ter origem asiática, o Brasil é o maior produtor e o seu cultivo está em terceiro lugar como cultura temporária em termos de ocupação de áreas no país.

A indústria canavieira contribui para o desenvolvimento econômico e social do país, é responsável por cerca de $50 \%$ das exportações mundiais de açúcar e consolida o Brasil como líder absoluto na produção de etanol (CONAB, 2009).

No processo de industrialização da cana-de-açúcar obtêm-se o açúcar e o álcool (anidro e hidratado). E como resíduos o bagaço, o vinhoto e a torta de filtro. O bagaço é um resíduo lignocelulósico fibroso obtido da última moagem da cana e é caracterizado como um material orgânico rico em polissacarídeos. É formado por um conjunto de partículas heterogêneas que possuem como componentes a celulose, a hemicelulose (presentes em sua parede celular) e a lignina, constituindo mais de $75 \%$ da biomassa vegetal da planta (SANCHEZ et al., 2010).

Com o aumento do cultivo da cana-de-açúcar no Brasil o bagaço torna-se um resíduo agroindustrial cada vez mais volumoso. Seu descarte é um problema devido ao seu grande acúmulo no ambiente. Por isso, a busca por meios e alternativas para a seu reaproveitamento tem aumentado nas últimas décadas.

Nas usinas sucroalcooleiras o bagaço é transformado em combustível para a geração de energia elétrica. Cerca de uma tonelada de cana-de-açúcar gera em torno de $320 \mathrm{~kg}$ de bagaço, dos quais $90 \%$ são usados na produção de energia. A importância da cogeração de energia na região Nordeste do Brasil utilizando o bagaço reside no fato de que ela coincide com o período de seca dos reservatórios das usinas hidrelétricas e, dessa forma, o uso do bagaço como combustível adquire um importante caráter complementar para o sistema energético nas usinas (UNICA, 2011).

De acordo com a CONAB (2015) a produção de cana-de-açúcar no Brasil teve um aumento de $3,5 \%$ (20,4 milhões de toneladas) em relação à safra de 2014/2015. No Nordeste, o estado do Maranhão se destacou sendo o quinto maior produtor da região. Sua safra em 2015/2016 foi estimada em 2 milhões e 689 mil toneladas de cana-de-açúcar e 194,4 milhões de litros de etanol, um aumento de 8,3\% em relação à safra 2014/2015. 
As principais usinas sucroalcooleiras no estado do Maranhão estão localizadas nos municípios de Coelho Neto (Usina de Itajubara S.A.), Aldeias Altas (Usina Itapecuru Bioenergia T.G Agroindustrial Ltda.), Campestre do Maranhão (Maity Bioenergia S/A) e São Raimundo das Mangabeiras (Usina Agro Serra).

Como um grande produtor da cana-de-açúcar, a agroindústria sucroalcooleira no estado do Maranhão gera também grandes quantidades de resíduos. O bagaço da cana-de-açúcar e o seu resíduo, as cinzas, podem ser empregados na produção de uma série de novos materiais. Por exemplo, o bagaço da cana-de-açúcar (BCA) é empregado principalmente na produção de compósitos para painéis de madeira aglomerada, na alimentação de ruminantes, na combustão para cogeração de energia, como adubo para a compostagem, na produção de etanol de segunda geração, na composição de filtros orgânicos, na indústria de papel e celulose, na indústria farmacêutica e na produção de bioplásticos. Já as cinzas do bagaço da cana-de-açúcar (CBC) podem ser utilizadas na fabricação de cimento, concreto e argamassas, cerâmica vermelha, carvão e fertilizantes.

\section{A rizicultura maranhense}

Dos estados produtores de arroz no Brasil, a região Sul se destaca sendo a responsável por cerca de $60 \%$ do cultivo e produção deste cereal. No Brasil, os estados com maior produção são: Rio Grande do Sul, Mato Grosso, Santa Catarina, Maranhão e Paraná. Fora da região Sul, o estado do Maranhão se destaca. Segundo a Empresa Brasileira de Pesquisa Agropecuária - EMBRAPA (2013) foi por volta do século XVII, através dos açorianos, que o estado do Maranhão teve contato com o cultivo do arroz. A produção teve início no município de Carolina, ao sul do estado, e a sua produção de arroz servia para abastecer Portugal. Na década de 1970 o estado passou a ser o primeiro produtor nacional de arroz de terras altas e em 2013 o Maranhão foi o terceiro maior produtor do país, ficando atrás apenas dos estados da região Sul.

Os dez maiores produtores de arroz no estado do Maranhão são os municípios de Santa Luzia, Grajaú, Barra do Corda, Arari, Bom Jesus das Selvas, Mirador, Tuntum, Vitória do Mearim, São Domingos do Maranhão e Colinas.

Cerca de 10 milhões de toneladas de arroz são produzidas anualmente no Brasil e é enorme o volume gerado de resíduos dessa produção no país, como as cascas e as cinzas (que são resultantes da queima das cascas). Estes resíduos se tornam recursos que podem ser utilizados em atividades agrícolas, industriais, na construção civil e na geração de energia de forma a destinar um emprego para estes resíduos e contribuir para a substituição do uso de matérias-primas não renováveis.

Segundo Gastaldini e Irion (2001), após a colheita, o arroz passa pelo processo de beneficiamento onde o grão é descascado e tratado em indústrias especializadas. Na fase de beneficiamento, além do arroz, também são gerados resíduos, onde o principal é a casca de arroz. Além de sua abundância, a casca do arroz é considerada o resíduo vegetal que mais produz cinzas em seu processo de combustão (PRUDÊNCIO; SANTOS; DÁFICO, 2013).

De acordo com Prudêncio, Santos e Dáfico (2013) uma grande parte dessas cinzas apresenta características pozolânicas o que implica dizer que, 
isoladamente, as cinzas não possuem valor aglomerante, mas, quando finamente moídas e com a adição de água, conseguem reagir com o hidróxido de cálcio [Ca(OH)2] e formar compostos cimentantes. Nos países produtores de arroz, onde se encontra um alto volume de cinzas da casca, a indústria cimenteira emprega as cinzas na produção de cimento como forma de reaproveitamento deste resíduo.

Atualmente as principais consumidoras da casca de arroz são as empresas responsáveis pelo seu próprio beneficiamento, utilizando a casca como combustível para produzir calor no processo de secagem do cereal. Essas empresas, por se tratarem na maioria dos casos de empresas de pequeno porte, não são capazes de produzir formas adequadas para o processamento e o descarte das cinzas geradas, que são corriqueiramente depositadas em terrenos baldios ou lançadas em cursos d'água, gerando assim, poluição e contaminação dos mananciais.

Diante disso, muitos trabalhos vêm sendo desenvolvidos com a intenção de empregar os resíduos da produção arrozeira nos mais diversos setores industriais, mostrando que as possibilidades de emprego das cinzas da casca de arroz são mais vantajosas do que o seu descarte, já que estas podem resultar em vários subprodutos, como por exemplo, para a obtenção de sílica, carvão ativado, borracha natural e, principalmente, serem empregadas na construção civil (PRUDÊNCIO; SANTOS; DÁFICO, 2013).

\section{Indicadores de design}

De acordo com Hodge et al. (1999 apud SOUZA, 2007) os indicadores são sinais tipicamente mensuráveis, que podem refletir uma característica quantitativa ou qualitativa, de importância vital para que se possa fazer julgamentos sobre as condições atuais, passadas e futuras de um determinado sistema. A adoção de um conjunto específico de indicadores, portanto, determinará a qualidade do sistema propriamente dito, sua história, interesses, necessidades, objetivos e tendências.

Por outro lado, como indica Pinter et al. (2000 apud SOUZA, 2007), os indicadores podem ser definidos como variáveis de um sistema, que expressam e comunicam informações importantes para determinado público. Esses valores adotados pela sociedade definem a atenção dada às particularidades de cada subsistema, bem como, suas inter-relações e capacidades de interação, contribuindo de modo significativo para a evolução da cultura e continuidade da vida em conjunto. Desta forma, criar um sistema de medidas significa valorar, ou seja, atribuir significados a determinados elementos do sistema, qualificá-los e quantificá-los sob óticas pré-determinadas e, por fim, assumir o controle sobre eles. Os indicadores provêm, assim, informação essencial sobre um sistema, facilitando a orientação e a tomada de decisão em um mundo complexo (BOSSEL, 1999 apud SOUZA, 2007).

Para auxiliar no entendimento dos objetivos contidos nos indicadores de design em projetos de valorização dos resíduos da construção civil, da indústria sucroalcooleira e da rizicultura no Maranhão fez-se necessário estabelecê-los a partir dos três níveis de tomada de decisão baseados na Gestão do design, conforme a Figura 2. 
Figura 2 - Objetivos dos indicadores em cada nível de tomada de decisão

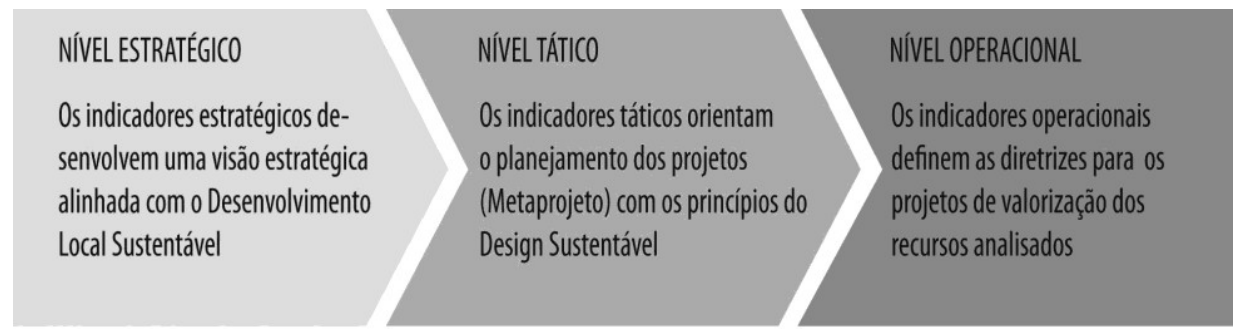

Fonte: próprio autor baseado em Mozota et al. (2011).

Neste trabalho os indicadores de nível estratégico são aqueles que propiciam uma atuação capaz de influir na formação e na transformação da visão estratégica geral do empreendedor e administrador, buscando direcionar a obtenção de resultados alinhados com o desenvolvimento local sustentável.

Os indicadores de nível tático são orientadores funcionais que se referem aos princípios do Design Sustentável e as abordagens de projeto relacionadas que guiarão os designers no planejamento dos projetos específicos de design, ou seja, contribuindo com a fase metaprojetual.

Os indicadores de nível operacional são os requisitos e diretrizes de projeto propriamente ditos. Referem-se diretamente aos resíduos da construção civil, da indústria sucroalcooleira e da rizicultura no Maranhão. Tais indicadores funcionam como guias para a execução e implementação dos futuros projetos de design que envolvem tais recursos. Estes indicadores auxiliam também no processo de controle da qualidade e avaliação da eficiência e efetividade das ações de design implementadas.

O conjunto dos indicadores estratégicos e táticos apresentados foi coletado e classificado a partir do trabalho de Levantamento Bibliográfico Narrativo que compreendeu as áreas do Design relacionadas com a sustentabilidade e a valorização dos recursos locais na etapa de Pré-desenvolvimento deste trabalho.

Já os indicadores operacionais foram obtidos a partir do trabalho de Revisão Bibliográfica Sistemática executado a partir do roteiro apresentado por Conforto, Amaral e Silva (2011) e abrangeu as áreas dos resíduos da construção civil, da indústria sucroalcooleira e da rizicultura através da análise dos artigos que descrevem pesquisas no Brasil que abordam estes assuntos.

A leitura dos indicadores com base nos níveis estratégico, tático e operacional permite que haja uma concatenação das ações de design propostas pelos indicadores, conforme a Figura 3, auxiliando na definição da direção estratégica para os projetos e na compreensão da viabilidade e da factibilidade das ações de design planejadas. Neste trabalho, a direção estratégica está alinhada com as ideias, conceitos e princípios que regem a sustentabilidade (em suas dimensões) e em seus desdobramentos nas ações de design sustentável que proporcionem a valorização dos recursos tratados neste estudo. 
Figura 3 - Indicadores de design propostos

\section{INDICADORES DE DESIGN}

\begin{tabular}{|c|c|c|}
\hline NIVEL ESTRATÉGICO & NIVEL TÁTICO & NIVEL OPERACIONAL \\
\hline $\begin{array}{l}\text { - Buscar a inovação radical } \\
\text { sustentável }\end{array}$ & $\begin{array}{l}\text { - Orientar o projeto a partir dos } \\
\text { princípios do Design Socialmente }\end{array}$ & $\begin{array}{l}\text { - Estabelecer diretrizes e requi- } \\
\text { sitos para contemplar a susten- }\end{array}$ \\
\hline - Promover estilos de vida & Responsavel & tabilldade ambiental, soclal e \\
\hline sustentáveis & - Orientar o projeto a partir & tos e/ou serviços desenvolvidos e \\
\hline $\begin{array}{l}\text { - Promover a ecoeficiência } \\
\text { sistêmica através da intearacão }\end{array}$ & $\begin{array}{l}\text { aos principios do Uesign para } 0 \\
\text { Território }\end{array}$ & nos resultados obtidos \\
\hline de empresas & - Proporcionar a interação e inte- & $\begin{array}{l}\text { - Estabelecer alretrizes e requisl- } \\
\text { tos gue proporcionem e desen- }\end{array}$ \\
\hline $\begin{array}{l}\text { - Promover a responsabilidade } \\
\text { social }\end{array}$ & $\begin{array}{l}\text { gração do projeto com as organi- } \\
\text { zaçôes colaborativas locais }\end{array}$ & volvimento do território \\
\hline $\begin{array}{l}\text { - Apoiar empreendimentos } \\
\text { colaborativos }\end{array}$ & $\begin{array}{l}\text { - Conceber o projeto como um } \\
\text { processo de Co-design }\end{array}$ & $\begin{array}{l}\text { - Estimular a organizaçao de } \\
\text { Comunidades Criativas }\end{array}$ \\
\hline $\begin{array}{l}\text { - Promover o reconhecimento e } \\
\text { a preservação da identidade e da } \\
\text { cultura local }\end{array}$ & $\begin{array}{l}\text { - Projetar a partir das identidades } \\
\text { locais } \\
\text { - Promover a certificação dos }\end{array}$ & \\
\hline $\begin{array}{l}\text { - Apoiar a construção de arranjos } \\
\text { produtivos locais }\end{array}$ & produtos de origem & \\
\hline
\end{tabular}

Fonte: próprio autor baseado em Manzini e Vezzoli (2008), Manzini (2008), Vezzoli (2010), Santos et al. (2011), Krucken (2009), Oliveira (2009), Trevisan (2006).

A partir do estudo das características, os usos e as tecnologias envolvidas nos processos de obtenção, manipulação e beneficiamento da cana-de-açúcar, foi possível organizar um conjunto de indicadores de design específicos para a valorização dos resíduos gerados pela indústria sucroalcooleira maranhense, conforme o Quadro 2.

Quadro 2 - Indicadores de design para a valorização dos resíduos da indústria sucroalcooleira maranhense

\section{Indicador \\ Desenvolver produtos que utilizam o bagaço da cana-de- açúcar (BCA) como composto orgânico para o solo}

Desenvolver produtos que utilizam o bagaço da cana-deaçúcar (BCA) como filtro orgânico para o solo

Desenvolver produtos que utilizam papel e papelão obtidos a partir da celulose do bagaço da cana-deaçúcar (BCA)

Desenvolver produtos que utilizam painéis aglomerados com adição do bagaço da cana-de-açúcar (BCA)
O BCA como composto orgânico proporciona ao solo melhorias nas propriedades físicas, aumentando a capacidade de retenção de água e macroporosidade. Por suas características filtrantes, o BCA auxilia no tratamento de águas residuárias e na remoção de sólidos sedimentares e material orgânico atuando assim como um filtro orgânico.

Por ser um material composto por celulose, o BCA pode ser aplicado na produção de papéis e papelão.

A estrutura lignocelulósica do BCA é semelhante à da madeira. É uma matéria-prima de baixo custo, tem grande disponibilidade e propriedades físico-mecânicas que possibilitam a utilização em painéis aglomerados de madeira. A adição do BCA junto com madeira na confecção de painéis aglomerados contribui para redução do uso da madeira e o desmatamento de florestas nativas. Suas características físicas (absorção de 
Desenvolver produtos moldados a partir de materiais compósitos formados pela combinação de diferentes materiais com o bagaço da cana-de-açúcar (BCA)

Desenvolver produtos à base de bioplástico obtido a partir do açúcar da cana-de-açúcar

Desenvolver produtos que utilizam a adição mineral das cinzas da queima do bagaço da cana-de-açúcar (CBC) água e inchamento) e suas características mecânicas (módulo de elasticidade, ruptura e tração perpendicular) validam o uso do BCA em painéis aglomerados. O BCA pode ser utilizado em adição a materiais compósitos, formados pela combinação de dois ou mais diferentes materiais. Seu uso estende-se desde a indústria moveleira, automobilística até a construção civil. Estes materiais apresentam baixo custo, provêm de fontes renováveis e possuem baixa densidade. A obtenção de celulose a partir do BCA pode ser feita através de processos químicos, físicos ou enzimáticos e a tecnologia envolvida é relativamente simples para processamento e a confeç̧ão de produtos moldados. Com a tecnologia de obtenção de xilose é possível desenvolver materiais plásticos biodegradáveis a partir de culturas bacterianas alimentadas pelos açúcares (sacarose e glicose) produzidos pela cana-de-açúcar. As culturas bacterianas transformam os açúcares em grânulos, pequenas bolinhas intracelulares que são, na realidade, poliésteres.

A partir da queima do bagaço da cana-de-açúcar em caldeiras para a geração de energia são geradas as cinzas. Estas cinzas são constituídas basicamente de sílica $\left(\mathrm{SiO}^{2}\right)$ e que podem ser utilizadas como adição mineral na produção de materiais cimentícios (concretos e argamassas), na indústria cerâmica (tijolos solo-cimento) e na produção do biocarvão.

Fonte: Próprio autor (2016).

Com base na análise das características, os usos e as tecnologias envolvidas nos processos de obtenção, manipulação e beneficiamento do arroz, foi possível organizar um conjunto de indicadores de design específicos para a valorização dos resíduos da rizicultura maranhense, conforme o Quadro 3.

Quadro 3 - Indicadores de design para a valorização dos resíduos da rizicultura maranhense

Indicador

Desenvolver produtos a partir da casca do arroz

\section{Descrição}

A casca do arroz pode ser aplicada em diversos materiais: Em painéis aglomerados substituindo a madeira e com a aplicação de adesivo e parafina. Apresenta maior resistência ao ataque de fungos e cupins, porém, pode apresentar menor estabilidade dimensional e resistência mecânica; Em lajes cerâmicas a partir da colagem com cola branca das cascas inseridas nos vãos dos tijolos de argila oca. Apresenta uma alternativa de baixo custo capaz de reduzir significativamente os ruídos em casas e edifícios; Em tijolos a partir do processo de trituração das cascas em moinho de martelos, imersão em solução de cal hidratada, lavagem, secagem em estufa, mistura manual dos componentes obtendo o tijolo de solo-cimento. A utilização desse resíduo em cerca de $12 \%$ não compromete as propriedades mecânicas dos tijolos, tornando-se uma alternativa ambiental e econômica; E, substrato agrícola a casca de arroz deve ser carbonizada (submetida a uma queima não completa e controlada das cascas). A casca de arroz carbonizada é incorporada ao solo e pode ser utilizada como substrato para produção de mudas e para a reprodução de minhocas. Estes substratos maximizam as plântulas, aceleram o desenvolvimento das mudas, e aumentam a taxa de 
Desenvolver produtos a partir das cinzas da queima da casca do arroz reprodução das minhocas.

As cinzas da queima da casca do arroz podem ser aplicadas em diversos materiais: No cimento, massa cerâmica e argamassas através de processos constituídos por moagem, secagem e mistura, utilizando as cinzas da casca de arroz em proporções específicas de acordo com a finalidade; Na obtenção de sílica através de tratamento químico (por meio de ácido clorídrico, ácido sulfúrico ou hidróxido de sódio) e tratamento térmico (calcinação da casca do arroz). A sílica obtida possui diversas apliçções inclusive na construção civil. Misturada com alumina, obtém-se a mulita, a qual possui diversas aplicações na área de cerâmica avançada, funcional e estrutural, podendo também ser utilizada como substrato de circuito integrado no campo da eletrônica.

Fonte: Próprio autor (2016).

Com o estudo das características, os usos e as tecnologias envolvidas nos processos de obtenção, manipulação e beneficiamento dos resíduos da construção civil em São Luís, foi possível definir indicadores de design específicos para a valorização destes resíduos no Maranhão, conforme o Quadro 4.

Quadro 4 - Indicadores de design para a valorização dos resíduos da construção civil no Maranhão

Indicador

Desenvolver produtos a partir da reciclagem dos resíduos da construção civil

Desenvolver produtos a partir da introdução do resíduo misto em compostos cimentícios
Descrição

Os resíduos da construção civil (construção e demolição) podem ser utilizados como matéria prima para a produção de outros materiais empregados na construção civil. Eles podem ser utilizados na substituição de três tipos de materiais: agregados (podendo ser graúdos ou miúdos); aglomerantes (essa substituição pode ser de forma total ou parcial); e aditivos.

A partir da transformação do resíduo misto em agregado graúdo ou miúdo é possível inseri-lo em concretos simples (que não possuem armadura) e que não necessitam de altas resistências. Produtos cimentícios elaborados com a introdução do resíduo misto da construção civil possuem as seguintes características: maior absorção de água; maior porosidade e menor resistência devido à presença de agregado vermelho (cerâmica); maior resistência à compressão devido aos efeitos de atração física entre a porção fina das partículas de entulho (forças de Van der Waals) e obturação dos poros gerando maior compacidade à microestrutura da pasta cimentícia (grãos da mesma ordem do cimento, ou seja, efeito Filler).

Fonte: Próprio autor (2016)

\section{CONSIDERAÇÕES FINAIS}

As indicações de design propostas têm a finalidade de auxiliar na construção de novas hipóteses de projeto orientadas para a transformação das atividades locais na direção de um modelo, ao mesmo tempo, mais competitivo e sustentável. 
Como resposta aos objetivos definidos neste trabalho, foram propostos indicadores de design sustentável fundamentados e descritos a partir de princípios e diretrizes estratégicas que permitem o planejamento e a execução de ações de design, comunicação e gestão de negócios, estabelecidos a partir dos três níveis de tomada de decisão da Gestão do design com o qual administradores públicos, empreendedores, designers e planejadores locais podem estabelecer agendas e planos para o desenvolvimento local a partir da valorização dos recursos presentes no território.

Outrossim, no que tange os resíduos da construção civil, da indústria sucroalcooleira e da rizicultura no Maranhão, foram estabelecidos indicadores específicos que permitem direcionar, desde já, o desenvolvimento de produtos, serviços, comunicação e infra estruturas orientadas para o incremento da competitividade e da sustentabilidade das cadeias produtivas que envolvem estes recursos.

Quanto a continuidade deste trabalho e as recomendações para trabalhos futuros, sugere-se a identificação, o mapeamento e o levantamento das correlações para o uso estratégico de outros recursos identificados como relevantes para a economia do Maranhão, porém não analisados neste estudo, como o Açaí (Euterpe oleracea), a Carnaúba (Copernicia prunifera), o Jaborandi (Pilocarpus jaborandi), o Caju ((Anacardium occidentale), o Tucum (Bactris setosa), a Mamona (Ricinus communis), os recursos pesqueiros, a produção pecuária, a produção têxtil e artesanal maranhense.

Por fim, a discussão promovida por este trabalho convida os designers que atuam no Maranhão a proporem projetos focados nos recursos naturais e nas tradições culturais maranhenses, intervindo nos espaços onde o design ainda não colabora efetivamente para o desenvolvimento da região. 


\title{
Design indicators for the valorization of residues from the civil construction, from sugar and alcohol industry as well as from the rice growing in the state of Maranhão
}

\author{
ABSTRACT
}

Based on narrative bibliographic surveys and on systematic bibliographic review, this text present the results related to the valorization of residues from the civil construction, from the sugar and alcohol industry as well as from the rice growing in the state of Maranhão. They were extracted from a technical report about a strategic design research intended to the improve the local resources and products in the territory of Maranhão. The research aimed to develop a study to promote the competitiveness of the micro-regions in Maranhão through the valorization of the local natural patrimony under the technical point of view of the sustainable design. This work reflects the premise that the sustainable use of the great diversity of natural resources in Maranhão can generate wealth and improve the quality of life for a great portion of the population involved in the process of recycling and reuse of waste. As a result, this study provides specific design indicators that make possible the recovery of the waste from the civil construction, from the sugar and alcohol industry as well as from the rice growing in the state of Maranhão.

KEYWORDS: Sustainable design. Strategic design. Valorization of residues. 


\section{REFERÊNCIAS}

ABRELPE, Associação Brasileira de Empresas de Limpeza Pública e Resíduos Especiais. Panorama dos Resíduos Sólidos do Brasil 2014. Disponível em: <http://www.abrelpe.org.br/>. Acesso em 23 jan. 2016.

BANIAS, G. et al. Assessing Multiplecriteria For The Optimal Location of a Construction And Demolition Waste Management Facility. Building and Environment, Amsterdam, v. 45, p. 2317-2326. 2010.

BISTAGNINO, L. Design Sistemico. Progettare la sostenibilità produttiva e ambientale. Bra: Slow Food Editore, 2009.

CONAB. Acompanhamento da safra brasileira: cana-de-açúcar, primeiro levantamento, abril/2009. CONAB, Brasília, 2009. Disponível em:

<http://www.conab.gov.br/conabweb/download/safra/1cana_de_acucar>. Acesso em 17 dez. 2015.

CONAB. Acompanhamento da safra brasileira: cana-de-açúcar, v.2, n.2 segundo levantamento, agosto/2015. CONAB, Brasília, 2015. Disponível em: <http://www.conab.gov.br/OlalaCMS/uploads/arquivos/15_08_13_15_58_44_bo letim_cana_portugues_-_2o_lev_-_15-16.pdf>. Acesso em 17 dez. 2015.

CONFORTO, E. C.; AMARAL, D. C.; SILVA, S. L. D. Roteiro para revisão bibliográfica sistemática: aplicação no desenvolvimento de produtos e gerenciamento de projetos. 80 Congresso Brasileiro de Gestão de Desenvolvimento de Produto CBGDP. Anais... p.1-12. Porto Alegre, 2011.

DE GIORGI, C.; GERMAK, C. (Org.). Manufatto. ArtigianatoComunitàDesign. Milão: Silvana Editoriale, 2008.

DE MORAES, D. Metaprojeto: o design do design. São Paulo: Blucher, 2010.

EMBRAPA. Arroz do Maranhão: competitividade e tradição. São Luís: EMBRAPA, 2013. Disponível em:

<http://ainfo.cnptia.embrapa.br/digital/bitstream/item/83489/1/folder-arrozdo-maranhao.pdf>. Acesso em 23 jun. 2015. 
GASTALDINI, M.C. C; IRION, C. A. O. Levantamento Sanitário da Bacia do Rio Ibicuí: avaliação das cargas poluidoras atuais. In: Congresso Brasileiro de Engenharia Sanitária e Ambiental, 16 a 21 Set. 2001, João Pessoa. Anais... João Pessoa: ABES, 2001. Disponível em:<http://www.bvsde.paho.org/bvsaidis/saneab/brasil/iv025.pdf>. Acesso em: 26 jun. 2015.

GHOR, C. F. et. al. Um Método Para Revisão Sistemática da Literatura em Pesquisas de Engenharia de Produção. XXXIII Encontro Nacional de Engenharia de Produção, 8 a 11 de Out. 2013, Salvador. Anais... Disponível em:

<http://www.abepro.org.br/biblioteca/enegep2013_TN_STO_186_058_22376.pd $f>$. Acesso em 15 jul. 2015.

KOENIG, G. K. Il design è un pipistrello $1 / 2$ topo $1 / 2$ uccello. Storia e teoria del design. Florença: Ponte alle Grazie, 1995.

KRUCKEN, L. Design e Território: valorização de identidades e produtos locais. São Paulo: Studio Nobel, 2009.

MACHADO, F. B. P. Brasil, a doce terra. História do Setor. Agência Embrapa de Informação Tecnológica. EMBRAPA, Brasília, 2015. Disponível em:

$<$ https://www.agencia.cnptia.embrapa.br/Repositorio/historia_da_cana_000fhc6 2u4b02wyiv80efhb2attuk4ec.pdf>. Acesso em 17 dez. 2015.

MANZINI, E. Design para a inovação social e sustentabilidade: Comunidades criativas, organizações colaborativas e novas redes projetuais. Rio de Janeiro: Epapers, 2008.

MANZINI, E.; VEZZOLI, C. O Desenvolvimento de Produtos Sustentáveis: Os requisitos ambientais dos produtos industriais. 1a ed., 2a reimpressão. São Paulo: Editora da Universidade de São Paulo, 2008.

MOZOTA, B. B.; KLÖPSCH, C.; COSTA, F. C. X. Gestão do design: usando o design para construir valor de marca e inovação corporativa. Porto Alegre: Bookman, 2011.

OBSERVATÓRIO EUROPEU LEADER. La competitività dei territori rurali nel contesto globale. Costruire una strategia di sviluppo territoriale alla luce dell'esperienza Leader. Innovazione in ambiente rurale. Quaderno n. 6, fasc. 5, feb. 2001.

OLIVEIRA, J. A. P. (Org.). Pequenas empresas, arranjos produtivos locais e sustentabilidade. Rio de Janeiro: Editora FGV, 2009. 
PRUDÊNCIO JÚNIOR, L. R; SANTOS, S; DÁFICO, D. A. Cinza da Casca de Arroz. In: ROCHA, J. C.. VANDERLEY, M. J. Habitare ANTAC, Porto Alegre, vol. 4, p. 240-261, 2003. Disponível

em:<http://www.habitare.org.br/pdf/publicacoes/arquivos/132.pdf>. Acesso em: 27 jun. 2015.

RESOLUÇÃO CONAMA № 307/2002. Estabelece diretrizes, critérios e procedimentos para a gestão dos resíduos da construção civil. Data da legislação: 05/07/2002, Publicação DOU no 136, de 17 jul. 2002, p. 95-96. CONAMA. Disponível em: http://www.mma.gov.br/port/conama/legiabre.cfm?codlegi=307>. Acesso em: 10 jul. 2015.

SANCHEZ et al. Compósito de Resina de Poliéster Insaturado com Bagaço de Cana-de-Açúcar: Influência do Tratamento das Fibras nas Propriedades. Polímeros, vol. 20, n. 3, p. 194-200, 2010.

SANTOS, A. dos; MERINO, E. Diaz; ROSA, I.; RIBEIRO, E. Proposition of criteria for the economical dimension of Design for Sustainability. In: III International Symposium on Sustainable Design, 2011, Recife. Anais..., 2011.

SOUZA, P. F. A. Sustentabilidade e responsabilidade social no design do produto: rumo à definição de indicadores. 2007. 294 f. Tese (Doutorado em Arquitetura e Urbanismo) - Faculdade de Arquitetura e Urbanismo, Universidade de São Paulo, São Paulo, 2007.

THACKARA, J. In the bubble. Design per un futuro sostenibile. Turim: Umberto Allemandi \& C. , 2008.

TREVISAN, S. D. P. (Org.). Comunidades sustentáveis: a partir do turismo com base local. Ilhéus: Editus, 2006.

UNICA. Bagaço de cana pode ganhar valor substituindo areia na construção civil. União da Indústria de Cana-de-Açúcar. UNICA, 2011. Disponível em: <http://www.unica.com.br/noticias/show.asp?nwsCode=\%7B4E794FD3-7EC2403C-A66D- 325016046000\%7D >. Acesso em: 23 jul. 2015. 
VEZZOLI, C. Design de Sistemas para a Sustentabilidade. Teorias, métodos e ferramentas para o design sustentável de sistemas de satisfação. Salvador: EDUFBA, 2010.

VOSGERAU, D.S.A.R.; ROMANOWSKI, J. P. Estudos de revisão: implicações conceituais e metodológicas. Diálogo Educacional, Curitiba, v. 14, n. 41, p. 165189, jan./abr. 2014. 
Recebido: 18 dez 2016

Aprovado: 14 fev. 2017

DOI: 10.3895/gi.v13n1.5231

Como citar:

LUCCA, A. S. et al. Indicadores de design para a valorização dos resíduos da construção civil, da Indústria sucroalcooleira e da rizicultura no maranhão. R. Gest. Industr., Ponta Grossa, v. 13, n. 1, p. 157-175, jan./mar. 2017. Disponível em: <https://periodicos.utfpr.edu.br/rgi>. Acesso em: XXX

Correspondência:

André de Souza Lucca

Cidade Universitária, Av. dos Portugueses, 1966, São Luís, Maranhão, Brasil.

Direito autoral: Este artigo está licenciado sob os termos da Licença Creative Commons-Atribuição 4.0

Internacional.

\section{(c) (1)}

